\title{
Supplementary Information for Fast Surface Dynamics on a Metallic Glass Nanowire
}

AUTHOR NAMES: Debaditya Chatterjee ${ }^{1}$, Ajay Annamareddy' ${ }^{1}$ Jittisa Ketkaew², Jan Schroers ${ }^{2}$, Dane Morgan ${ }^{1}$, Paul M. Voyles ${ }^{1}$

\section{AUTHOR ADDRESSES:}

${ }^{1}$ Department of Materials Science and Engineering, University of Wisconsin - Madison, Madison WI 53706, USA.

${ }^{2}$ Department of Mechanical Engineering and Materials Science, Yale University, New Haven, CT 06520, USA.

*Corresponding author. Email: paul.voyles@wisc.edu

\section{Supplementary figures}
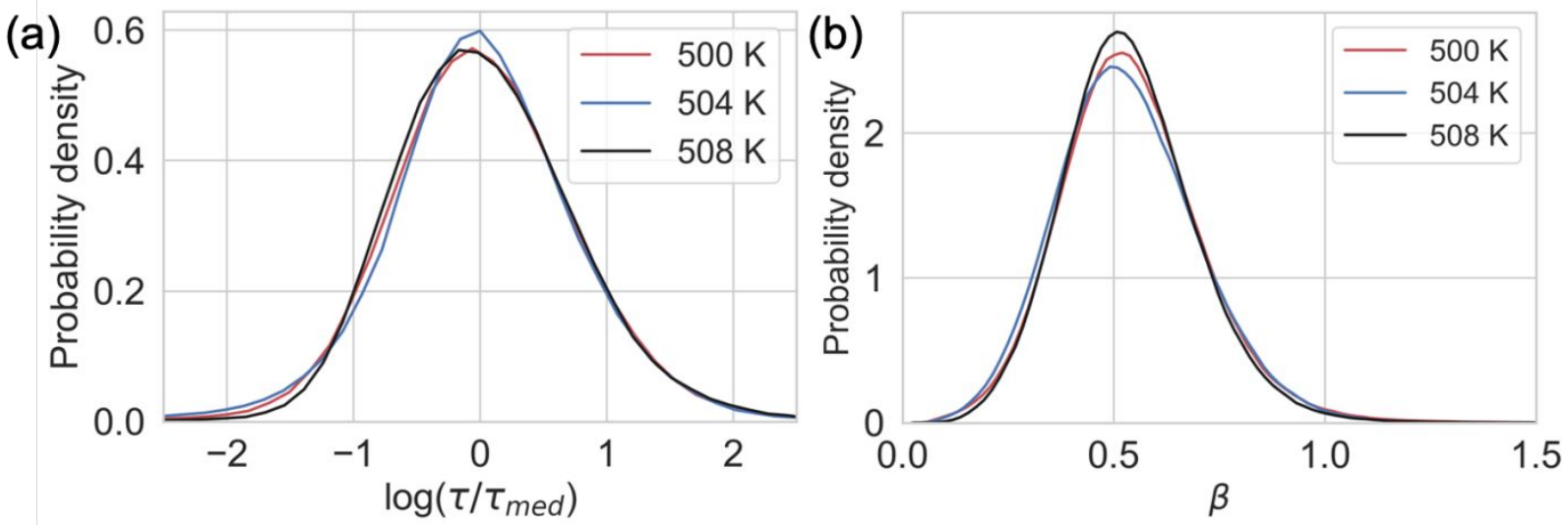

Supplementary Figure 1. (a) The distributions of the near-surface relaxation time $\tau$ normalized by the median values in $\log$ scale at $500 \mathrm{~K}, 504 \mathrm{~K}$, and $508 \mathrm{~K}$, (b) The distributions of near-surface $\beta$ at $500 \mathrm{~K}, 504 \mathrm{~K}$, and $508 \mathrm{~K}$. 

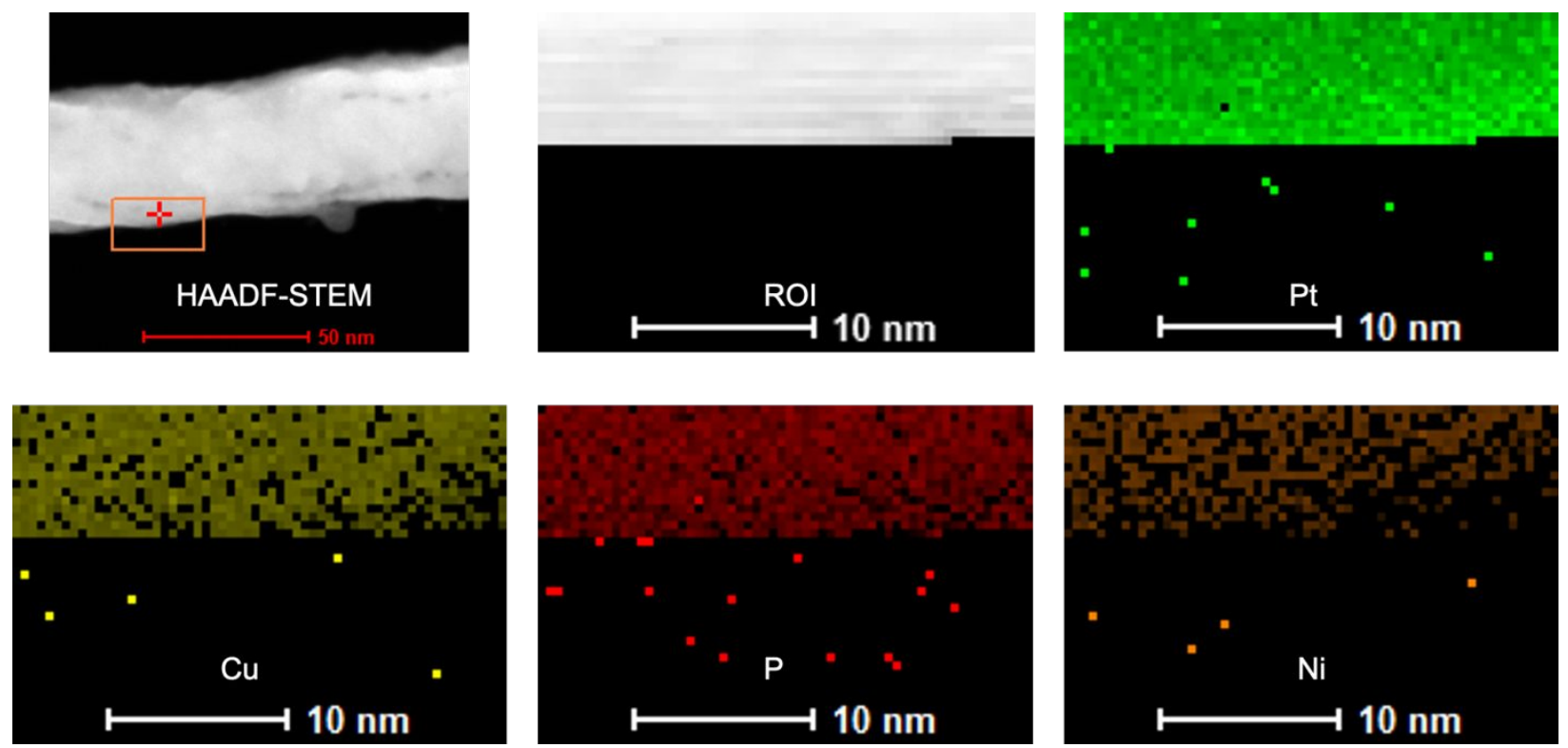

Supplementary figure 2. STEM-EDS mapping of a $\mathrm{Pt}_{57.5} \mathrm{Cu}_{14.7} \mathrm{Ni}_{5.3} \mathrm{P}_{22.5}$ nanowire annealed at $492 \mathrm{~K}$ for 3 hours, showing no evidence of surface segregation. Acquisition was performed using 60 positions along $\mathrm{X}$ direction with $2 \mathrm{~s}$ dwell time.
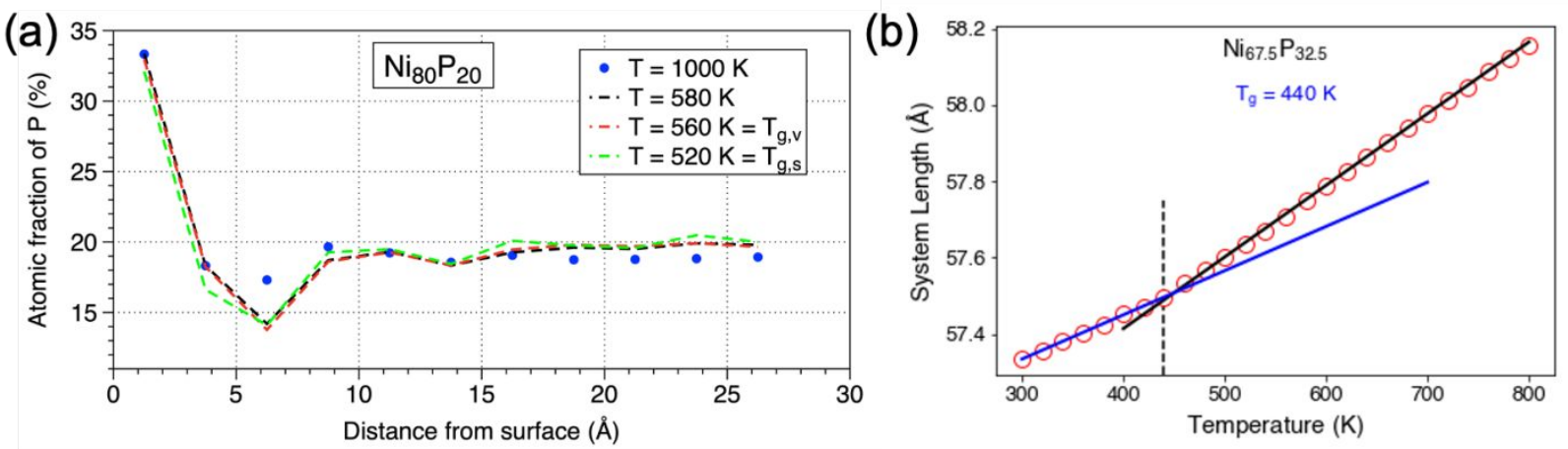

Supplementary figure 3. (a) Composition profile of $\mathrm{P}$ atoms in the $\mathrm{MD}$ simulated $\mathrm{Ni}_{80} \mathrm{P}_{20}$ system showing surface segregation over a wide temperature range, (b) $T_{g, v}$ determined via MD simulations for the P-rich surface layer composition is $440 \mathrm{~K}$. 
(a)

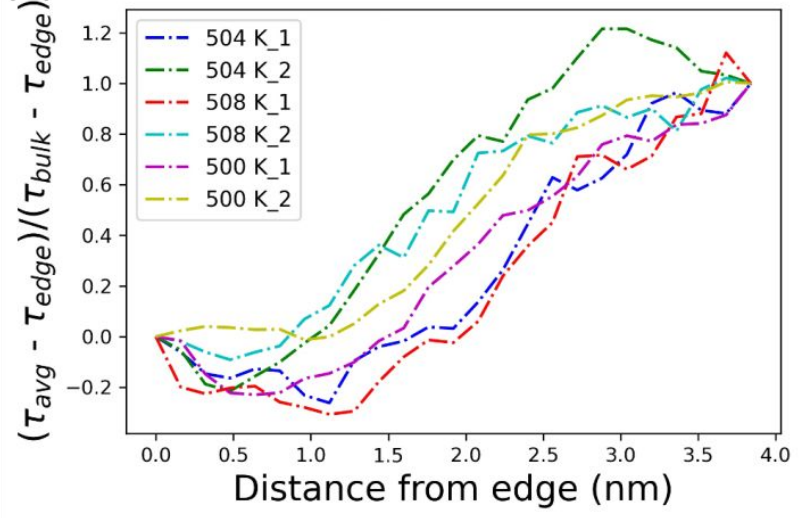

(b)

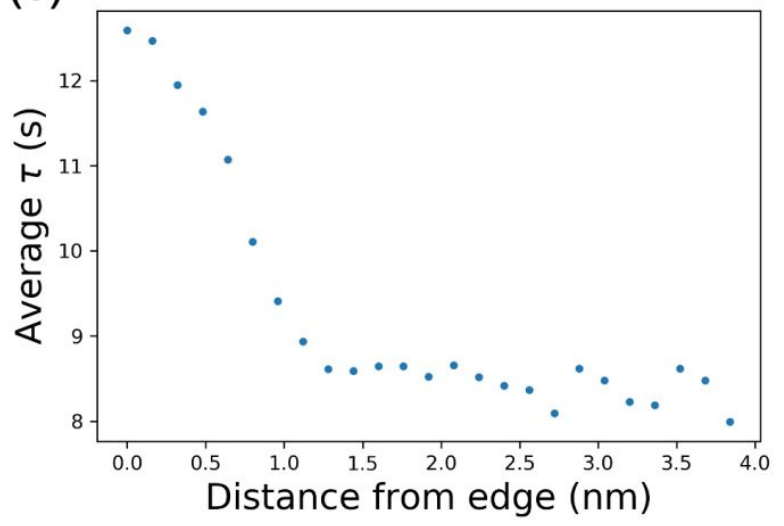

Supplementary figure 4. (a) Average normalized relaxation time profiles from the surface at different temperatures for uncoated nanowires, (b) Average relaxation time profile from the surface for nanowire coated with $10 \mathrm{~nm}$ amorphous carbon at $519 \mathrm{~K}$. 